\title{
Experimental retinal branch vein occlusion in rhesus monkeys. II. Retinal blood flow studies
}

\author{
D. A. ROSEN, J. MARSHALl, EVA M. KOHNER, A. M. HAMILTON, AND \\ C. T. DOLLERY \\ From the Royal Postgraduate Medical School, Hammersmith Hospital, and Institute of Ophthalmology, \\ University of London
}

SUMMARY Experimental branch vein occlusion by laser photocoagulation in the rhesus monkey leads to early, marked, and lasting reduction of blood flow to the affected retinal region. The radioactive microsphere method demonstrates this reduction of blood flow in both gamma counting and autoradiography. The reduction of flow becomes evident as early as 2 hours after occlusion and persists up to 1 week. The mechanism of the altered flow is discussed.

The clinical features of retinal branch vein occlusion are well established both in man (Raitta et al., 1971) and in experimental animals (Hayreh, 1965; Fujino et al., 1968; Kohner et al., 1970; Hamilton et al., 1974). Considerable doubt remains concerning the role of arterial disease and perfusion of the affected retina in the pathogenesis of the disorder. In particular it is not known what the cause of capillary nonperfusion is, nor is it known how blood flow is changed in the immediate and early days following occlusion.

Clinical methods for the measurement of retinal blood flow in man are not available at the present time. In experimental animals the intracardiac injection of radioactively (strontium-85) tagged microspheres $(15 \pm 5 \mu \mathrm{m})$ give a reliable measure of regional blood flow (Hoff brand and Forsyth, 1969). We employed a modification of this method (Alm and Bill, 1972, 1973) in an attempt to assess changes in retinal blood flow following experimental occlusion of retinal veins in the rhesus monkey.

\section{Methods}

PREPARATION OF ANIMALS

Rhesus monkeys weighing 3 to $5 \mathrm{~kg}$ were anaesthetised as described in the previous paper (Hamilton et al., 1979). Retinal colour photographs and fluorescein angiography (intravenous $10 \%$ sodium fluorescein) facilitated the selection of veins for occlusion. In all instances the venous segment

Address for reprints: Dr Eva M. Kohner, Royal Postgraduate Medical School, Hammersmith Hospital, Ducane Road, London W12 0HS occluded was within 1 disc diameter of the disc but sufficiently removed from an associated arteriole to avoid the possibility of damaging the arteriole during the occlusion. Variation between individual animals led to the production of superior temporal branch vein occlusion in some animals and superior hemisphere vein occlusion in others (Table 1). One eye, the left, was treated, while the right served as an untreated control. In 1 animal (31) the superior temporal veins in both eyes were occluded. In this animal the right eye was occluded 1 hour before injection of microspheres. Two animals (Nos. 33 and 49) were left untreated in order to assess eye-to-eye and segment-to-segment variation.

Occlusion was achieved by using an argon laser (Coherent Radiation Model 800) with a 50- $\mu \mathrm{m}$ spot size, an exposure time of 0.2 seconds, and energy levels of 100 to $250 \mathrm{~mW}$. Repeated applications were made until the treated segment of vein appeared occluded on ophthalmoscopic examination. The occlusion was confirmed by fluorescein angiography carried out $\frac{1}{2}$ to 1 hour after coagulation. If subsequent examination, after hours or days, revealed resumption of blood flow, the initially treated segment was again coagulated. Most veins remained occluded after a single treatment; in some up to 3 sessions of treatment were necessary (Table 1). The length of follow-up was calculated from the time a permanent occlusion was achieved.

On the day of enucleation colour photography and fluorescein angiography were performed on both eyes in each animal. Femoral artery catheters were introduced into both legs to permit monitoring of $\mathrm{pH}, \mathrm{PO}_{2}$ and $\mathrm{PCO}_{2}$ and blood pressure and to allow the measured withdrawal of arterial blood. 
Table 1 Results of treatment

\begin{tabular}{|c|c|c|c|c|c|c|}
\hline Animal & $\begin{array}{l}\text { Treatment } \\
\text { sessions }\end{array}$ & $\begin{array}{l}\text { Duration of } \\
\text { occlusion }\end{array}$ & $\begin{array}{l}\text { Location of } \\
\text { occlusion }\end{array}$ & Dose $85 S r \mu C$ & $\begin{array}{l}\mathbf{A} / \mathbf{B} \times 100 \\
(\%)\end{array}$ & $\begin{array}{l}A / C \times 100 \\
(\%)\end{array}$ \\
\hline 27 & 3 & 2 hours & ST & 40 & $11 \cdot 4$ & $38 \cdot 0$ \\
\hline 52 & 2 & 6 hours & SH & 139 & $21 \cdot 1$ & $13 \cdot 2$ \\
\hline 50 & 2 & 1 day & SH & 250 & $35 \cdot 1$ & $30 \cdot 8$ \\
\hline 32 & 1 & 3 days & ST & 83 & $59 \cdot 4$ & $27 \cdot 9$ \\
\hline 34 & 1 & 5 days & ST & 98 & $2 \cdot 3$ & $1 \cdot 2$ \\
\hline 35 & 1 & 5 days & ST & 98 & $36 \cdot 1$ & $63 \cdot 8$ \\
\hline 29 & 1 & 1 week & ST & 60 & $29 \cdot 9$ & $19 \cdot 3$ \\
\hline 30 & 1 & 1 week & SH & $41 \cdot 5$ & $37 \cdot 5$ & $60 \cdot 0$ \\
\hline $31 *$ & 1 & 1 week & ST & 89 & $73 \cdot 7$ & $52 \cdot 8$ \\
\hline 28 & 2 & 2 weeks & ST & 58 & $100 \cdot 0$ & $91 \cdot 5$ \\
\hline \multicolumn{7}{|c|}{ Controls } \\
\hline 33 & - & - & - & $9 \cdot 0$ & $100 \cdot 0$ & $100 \cdot 0$ \\
\hline 49 & - & - & 一 & $1201 \cdot 0$ & $120 \cdot 1$ & $91 \cdot 5$ \\
\hline
\end{tabular}

$A=$ 'Treated' area. $B=$ Comparable area in opposite eye. $C=$ Adjacent untreated inferior retina in treated eye.

ST $=$ Superior temporal occlusion. SH = Superior hemisphere occlusion. "One hour's occlusion of superior temporal vein (untreated eye)

When these parameters were constant and normal, the left thorax was entered in the fifth intercostal space, the pericardium was incised, and a rapid injection of ${ }^{85} \mathrm{Sr}$-tagged carbonised microspheres (obtained from Riker Laboratories, Loughborough, Leicestershire, $15 \pm 5 \mu \mathrm{m}$ diameter, total dose 40 to $260 \mu \mathrm{Ci}$ ) in a $2-\mathrm{ml}$ agitated suspension was made into the left ventricle near its apex. Simultaneously arterial blood was withdrawn by an automatic infusion-withdrawal pump (Harvard Model 600-950 VDC) for 15 to 40 seconds from the femoral artery. The sample provided an arterial blood standard for radioactivity measurement as well as a means of calculating cardiac output. Immediately after the withdrawal of the arterial sample cardiac arrest was accomplished with rapid intravenous injection of potassium chloride.

\section{PREPARATION OF EYES}

For radioactivity counting. The eyes were enucleated and dissected in the coronal plane immediately posterior to the ciliary body. Hyaluronidase (1500 units) was injected into the posterior vitreous, to obtain easy separation of the ocular coats and vitreous. This was found to be unnecessary in the later experiments. The posterior ocular segments were orientated under a dissecting microscope, and radial cuts were made close to the vertical and horizontal meridians of sufficient length to allow the ocular coats to be flattened by pins to dental wax discs contained in Petri dishes or on to a moist pad of hardened filter paper (Whatman no. 50). Care was taken to avoid transecting larger retinal vessels. Discs of retina and choroid were incised together with a 5-mm diameter corneal trephine in the locations indicated in Fig. 1. The exact location varied from animal to animal depending on the distribution of the infarct. Particular efforts were made to excise tissue from corresponding locations of the 2 eyes of each animal. The discs of retina and choroid were removed from underlying sclera. The choroidal and retinal components were separated with care under microscopic magnification by means

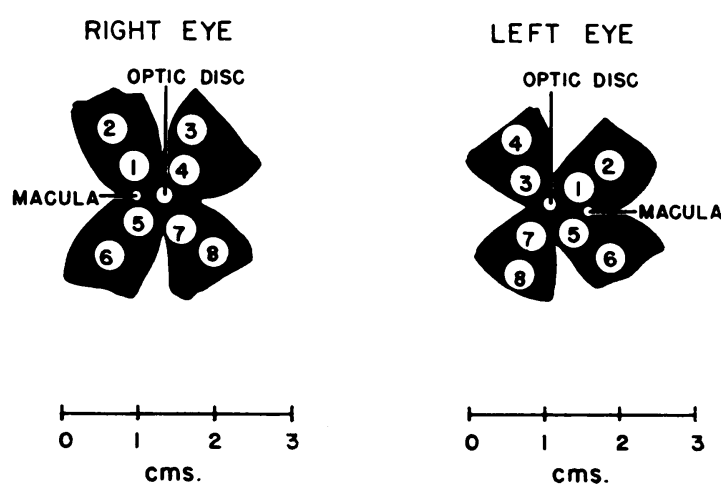

Fig. 1 Pattern of dissection of retinae for radioactivity counting 
of a corneal spatula and sable brush. They were transferred on preweighed squares of lens paper to siliconised glass tubes for radioactivity counting. Choroid blood and radioactive standard samples were counted for 10 minutes and retinal discs for 30 minutes in a Wallac 80000 automatic gamma counter.

The tissue samples were allowed to dry to constant weight for a minimim of 24 hours and were weighed on a Cahn Electrobalance (Model G).

After subtraction of the background radioactivity tissue radioactivity was calculated as counts per minute per milligramme of dry weight. Retinal counts only will be reported in this paper.

For autoradiography. Radial cuts were made similar to those above, before the retinae were separated from their respective choroids with sable brushes. The isolated retinae were then flattened on large microscope slides $(50 \times 76 \mathrm{~mm})$ and overlayed with a portion of a second microscope slide. The resultant slide-tissue matrix was placed in an empty Petri dish, which was slowly filled with a fixative solution composed of $2.5 \%$ gluteraldehyde buffered in $0.1 \mathrm{M}$ sodium cacodylate containing $10 \mathrm{mg} / \mathrm{ml}$ calcium chloride with a final pH of 7.4. After several minutes the upper slide was carefully oscillated to allow penetration of the fixative but with care to prevent deformation of the retina.

After overnight fixation preparations were washed in a sucrose buffer and mounted flat on clean glass slides smeared with egg albumen. The preparations were air-dried for 2 days before being transferred to a dark room, where they were placed tissue side down on sheets of Structrix 7 (Agfa) $x$-ray film. The slides were stabilised with small brass weights and the orientation recorded by marks placed on the film around the edges of the slide. The preparations were stored in a light-tight box at $4^{\circ} \mathrm{C}$ for 3 days. After this the film was carefully separated from the retina and developed in D17 (Kodak) for 5 minutes before being fixed in Kodak acid fixing powder.

The developed autoradiographs were orientated over their initiating tissue samples by the marks made on the film, and the retinal boundaries and topography were traced on to the autoradiograph in ink (Figs. 2, 3, 4).

\section{Results}

Two control animals were studied after injection of radioactive microspheres. Matching areas of the retinae of their left and right eyes were excised. The ratio of counts in these areas was 1.00 in monkey no. 33 and 0.91 in monkey no. 49 . This indicates uniform entry of microspheres into undamaged retinal tissue of the 2 eyes.
The results in the 10 experimental animals studied by radioative counting are given in Table 1 . The mean ratio of counts in the area of the occluded vein compared with the matching area in the opposite retina was $0 \cdot 41$. When compared with the adjacent inferior retina of the same eye the ratio was 0.40 .

A comparison was also made between the matching control area in the opposite retina and the adjacent control area. The matching: adjacent ratio averaged 1:16. This finding is of interest as it confirms the reproducibility of the measurements for similar treated areas, and it indicates that there was no compensatory increase of flow through the adjacent retinal area as a consequence of the vein occlusion.

The anomalous result in monkey no. 28 which had no reduction of blood flow at the time of measurement 2 weeks after occlusion may be explained by the development of a profuse collateral supply. This was noted on the fluorescein angiograms.

The reduction of radioactivity was similar in eyes which had superior temporal and superior hemisphere branch vein occlusions, and the extent of reduction was independent of the duration of the occlusion. A considerable reduction of flow was evident at the earliest times of measurement after vein occlusion, 2 and 6 hours. The reduction of flow in the group was highly significant $(\mathrm{P}<0.01)$.

Five eyes were studied by autoradiography. Two were control retinae which showed an even distribution of flow, apart from the macular area, in which there was a greater number of microspheres (Fig. 2). The 2 animals with vein occlusions both had obstructed hemisphere veins, one of 5 days' and the other of 1 week's duration. In one (5 days) there was very little penetration of spheres into the occluded area and in the other (1 week) markedly less than comparable areas of the normal retina (Figs. 3, 4).

\section{Discussion}

We have demonstrated that between the durations of 2 hours and 1 week laser-induced retinal branch vein occlusion in the monkey leads to markedly reduced entry of tagged microspheres into the affected region. This indicates a reduction of blood flow. We chose microspheres with a diameter of $15 \pm 5 \mu \mathrm{m}$ in the expectation that the spheres would become impacted in capillaries and precapillary arterioles. Our earlier experience with the experimental vein occlusion model indicates that, as judged by fluorescein angiography and morphological studies, capillary closure only rarely occurs earlier than 24 to 48 hours (Hockley et al., 1979). Fluorescein studies, however, show an early delay of arterial 

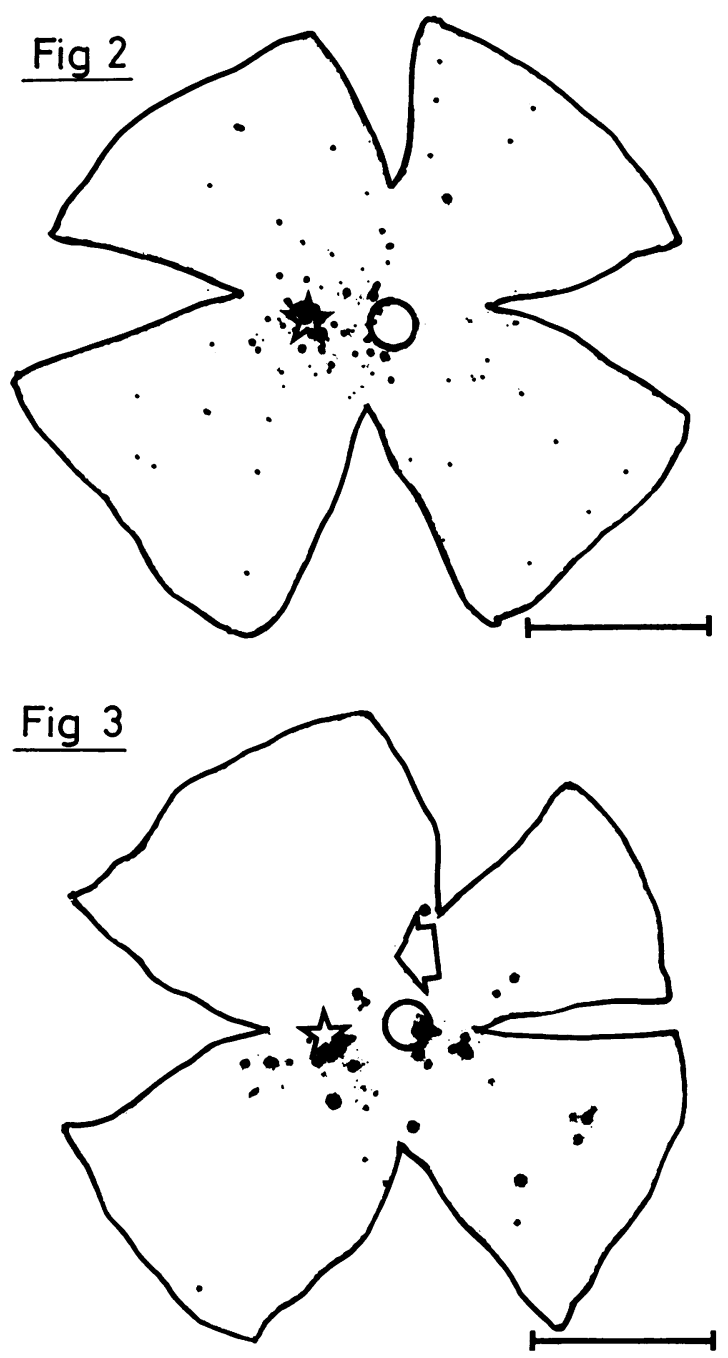

perfusion of the affected area (Hamilton et al., 1979).

The reduced radioactivity as early as 2 hours in the counting experiments and 5 hours in the autoradiographic studies was therefore an interesting finding. Its origin is, however, unclear. Collapse of the retinal capillaries due to pressure by oedema was not found, nor could transmural pressure be sufficiently high. The most likely explanation is back pressure from the veins in which blood is stagnating at a time when collaterals of adequate diameter had no time to develop.

The results presented in Table 1 illustrate some of the difficulties of applying the microsphere method to small portions of tissue with a relatively poor blood supply such as the retina. Study of the radioautographs indicates that the number of micro-
Figs. 2, 3, 4 Autoradiographs of isolated monkey retinae after intracardiac injection of radioactively labelled microspheres. The position of the optic disc is indicated by an open circle and that of the macula by $a$ star. Bar $=1 \mathrm{~cm}$. (2) Autoradiograph of an untreated retina showing a relatively uniform distribution of label but with a concentrate around the macula. (3) Autoradiograph of a retina in which a superior hemisphere vein has been obstructed for 5 days. Note the reduction of the label in the superior temporal quadrant of the retina. (4) Autoradiograph of a retina in which a superior hemisphere vein had been occluded for 7 days. In this sample the reduction of label is most marked in the superior nasal quadrant

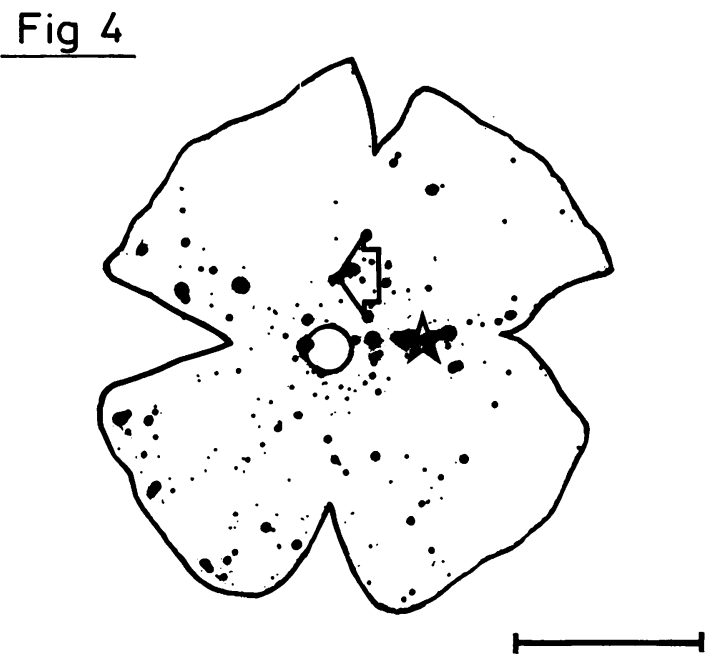

spheres lodged in a 5-mm diameter disc of retina might be small, and thus the statistics of counting would be poor. However, this would not explain the large differences between animals in the number of spheres entering similar areas of the retina. The explanation of this variability must lie in either uneven mixing of the microspheres in the flowing blood or highly variable retinal perfusion. As care was taken to study animals only when the blood gases and the blood pressure were stable, the former explanation seems more likely.

The relative sparsity of microspheres and the unevenness of their distribution also gave rise to difficulties in interpretation of the autoradiographic preparations. The differences in size and density of the photographic images suggest that it is not rare 
for more than one sphere to be lodged in a single minute vessel. Most probably this was the result of the flow pattern and the anatomy of the retinal circulation. In previous studies with glass spheres we have noted a tendency for the spheres to go repeatedly to the same vessel or area of the retina (Dollery et al., 1965). None the less, both the studies with the radioactive counting and the autoradiographic studies were in agreement as to the magnitude and the distribution of blood flow reduction.

This work was supported by the E. H. Botterell Fund of Queen's University, the Wellcome Trust, and the Medical Research Council.

\section{References}

Alm, A., and Bill, A. (1972). The oxygen supply to the retina. II. Effects of high intraocular pressure and increased arterial carbon dioxide tension on uveal and retinal blood flow in cats. Acta Physiologica Scandinavica, 84, 306-319.

Alm, A., and Bill, A. (1973). Ocular and optic nerve blood flow at normal and increased intraocular pressures in monkeys. A study with radioactively labelled microspheres including flow determinations in brain. Experimental Eye Research, 15, 15-29.

Dollery, C. 'T., Ramalho, P. S., Paterson, J. W., Hill, D. W., Henkind, P., Shakib, M., and Ashton, N. (1965). Retinal microemboli, experimental production of cotton-wool spots. Lancet, 1, 1303.

Fujino, T., Curtin, V. T., and Norton, E. W. D. (1968). Experimental central retinal vein occlusion: a comparison of intraocular and extraocular occlusion. Transactions of the American Ophthalmological Society, 66, 318-378.

Hamilton, A. M., Kohner, E. M., Rosen, D., and Bowbyes, J. (1974). Experimental venous occlusion. Proceedings of the Royal Society of Medicine, 67, 1045-1048.

Hamilton, A. M., Kohner, E. M., Rosen, D., Bird, A. C., and Dollery, C. T. (1979). Experimental retinal branch vein occlusion in rhesus monkeys. I. Clinical appearances. British Journal of Ophthalmology, 63, 377-387.

Hayreh, S. S. (1965). Occlusion of the central retinal vessels. British Journal of Ophthalmology, 49, 626-645.

Hockley, D. J., Tripathi, R. C., and Ashton, N. (1979). Experimental retinal branch vein occlusion in rhesus monkeys. III. Histopathological and electron microscopical studies. British Journal of Ophthalmology, 63, 393-411.

Hoff brand, B. I., and Forsyth, R. P. (1969). Validity studies of the radioactive microsphere method for the study of the distribution of cardiac output, organ blood flow and resistance in the conscious monkey. Cardiovascular Research, 3, 426-432.

Kohner, E. M., Dollery, C. T., Paterson, J. W., Bulpitt, C. J., Henkind, P., Shakib, M., and Oliveira, L. (1970). Experimental retinal branch vein occlusion. American Journal of Ophthalmology, 69, 778-782.

Raitta, C. (1965). Retinal vein occlusion. Acta Ophthalmologica, Suppl. 83, 1-125.

Wise, G. N., Dollery, C. T., and Henkind, P. (1971). The Retinal Circulation, pp. 349-364. Harper \& Row: New York. 